\title{
Clinical, Histological and Trichoscopic Correlations in Scalp Disorders
}

\author{
Alfredo Rossi $^{\mathrm{a}}$ Maria Caterina Fortuna ${ }^{\mathrm{a}}$ Giulia Pranteda ${ }^{\mathrm{a}}$ Valentina Garelli ${ }^{\mathrm{a}}$ \\ Donato Di Nunno ${ }^{a}$ Elena Mari ${ }^{a}$ Stefano Calvieri ${ }^{a}$ Marta Carlesimo ${ }^{b}$ \\ a Dipartimento di Medicina Interna e Specialità Mediche, Clinica Dermatologica, University of Rome 'Sapienza', and \\ bUOC Dermatologia, Ospedale Sant'Andrea, University of Rome 'Sapienza', Rome, Italy
}

\section{Key Words}

Dermatoscopy $\cdot$ Scalp diseases $\cdot$ Scarring

alopecia $\cdot$ Trichoscopic pattern

\begin{abstract}
Trichoscopy is the term coined for the dermoscopic imaging of scalp and hair. This diagnostic technique, simple and noninvasive, can be used as a handy bedside tool for the diagnosis and follow-up of hair and scalp disorders. It allows the recognition of morphologic structures not visible by the naked eye and provides the clinician with a range of dermoscopic findings necessary for differential diagnosis. Trichoscopy observation can be broadly grouped as interfollicular patterns and follicular patterns. Recently, a third mixed class, called the follicular plus interfollicular pattern, has been introduced. Some of these features are specific to a certain scalp disease, while others can be found in many hair disorders. Although studies suggest that the use of trichoscopy can improve clinical accuracy, further investigation is needed. This review provides update information on the trichoscopic features of the most common scalp disorders, striving to show a histopathological and clinical correlation.
\end{abstract}

(c) 2015 S. Karger AG, Basel

\section{Introduction}

Trichoscopy is a dermoscopic examination of the hair and scalp and is a simple, reproducible, easy to perform, noninvasive, harmless and validated instrumental analysis method, which allows, through the use of a manual or digital dermatoscope, the diagnosis and follow-up of various scalp diseases.

The term 'trichoscopy' is a term coined in 2006 by Rudnicka et al. [1] to indicate hair and scalp dermoscopy. Even though trichoscopy has gained popularity only recently, the use of this tool for the study of scalp diseases goes back to the 1990s. In 2004, Lacarrubba et al. [2] established that trichoscopy was able to enhance the diagnostic capability in some forms of hair loss, describing the characteristics of alopecia areata (AA).

In 2005, Olszewska and Rudnicka [3, 4] used the method to evaluate androgenetic alopecia (AGA) severity and its therapeutical follow-up. In 2006, Ross et al. [5] described specific trichoscopic features of certain hair and scalp diseases, classifying them as either follicular or interfollicular. Subsequently, a growing number of reports have defined the use of dermatoscopy in trichology, and in 2011, Rossi et al. [6] in- troduced the Videodermoscopy Scalp Psoriasis Severity Index (VSCAPSI) for the assessment of scalp psoriasis (PSO) severity using trichoscopy.

In particular through the study of the scalp surface and microcirculation morphology, the authors have identified a number of specific aspects, referred to as interfollicular pattern (vascular pattern and pigmented pattern) and follicular pattern $[5,7]$. This classification was revised in 2012 [8], with the addition of a third mixed class (follicular plus interfollicular pattern), since pustular and hyperkeratotic lesions can be detected in both locations. The sensitivity and specificity of these trichoscopic features for each scalp disease are often low; in fact, a single pattern can be observed in $>1$ of them: therefore, once again, anamnestic, clinical, trichoscopic and, in some cases, histopathological features lead to the correct diagnosis of hair and scalp disorders.

\section{Material and Methods}

Searching from 2006 to 2014 for the terms 'trichoscopy' and 'hair diseases dermatoscopy' in several reports in PubMed,

\section{KARGER 125}

(c) 2015 S. Karger AG, Base

$1018-8665 / 15 / 0000-0000 \$ 39.50 / 0$
Giulia Pranteda

Dipartimento di Medicina Interna e Specialità Mediche

Clinica Dermatologica, University of Rome 'Sapienza'

IT-00161 Rome (Italy)

E-Mail cpranteda@ libero.it 
we strove to provide a review that summarizes current knowledge about structures observed in trichoscopy and to show a clinical and histological correlation. Below, we report the main pattern observed in hair and scalp diseases.

\section{Interfollicular Pattern}

Based on the classification presented in the literature by Ross et al. [5], there are the vascular patterns and the pigment patterns (table 1).

\section{Vascular Pattern}

Simple Red Loops. These are multiple, relatively evenly spaced, fine, red, lassoshaped loops. They can be isolated or articulated with an underlying plexus of wider red lines best at $50 \times$ or higher magnification, with the camera probe angled tangentially. Simple loops can be present in some pathological conditions, excluding discoid lupus erythematosus (LED). Interfollicular simple red loops are structures that histologically correspond to the capillaries of dermal papillae. Ryan [9] postulated that the capillary loop morphology, corresponding to the dermal papilla capillaries, correlates with the state of the overlying epidermis; simple loops are associated with the presence of a scalp epidermis of normal thickness, so that their absence indicates atrophy. This is the reason why the loops are absent in LED, where epidermal atrophy is present. According to the report by Ross et al. [5], simple reed loops were more frequent observed in PSO and seborrheic dermatitis (SD). According to our experience, they can also be found in atopic dermatitis.

Twisted Red Loops. These are multiple, relatively evenly spaced, spiral-shaped twisted loops and are observed in cases of hypertrophy (acanthosis), in proportion to its degree; in fact, they are present in inflammatory diseases, characterized by epidermal hyperplasia, and are absent in the normal scalp. They appear as multiple red dots at low magnification $(10-20 \times)$, and as polymorphous beaded lines and circles at high magnification $(40 \times)$. Histologically, they correspond to dilated capillaries in dermal papillae, and their number and visibility correlates with disease severity. Ross et al. [5] reported in almost all cases of PSO a frequency of 23/23 and in folliculitis decalvans (FD) one of 4/4. In PSO, the different aspects of the vessels during the elongation of the papillae correspond to the place of maximum activity of the disease. More- over, their morphology varies, depending on the viewpoint of the observer, being conditioned by the position of the dermatoscope compared to the vessels themselves, so that when the instrument is placed transversely with respect to the surface of the scalp, they appear as red dots, blood cells (number of red dots arranged in a ring net or in irregular circles) and glomeruli (vascular pattern, globular pattern and glomerular pattern, respectively); however, when the tool is placed tangentially, the vessels appear as hairpins (twisted red loops) [10].

Arborizing Red Lines. These appear as red lines, similarly structured to loops but with a wider caliber, and are observed in a variable number of normal and pathological scalp; they correspond to the subpapillary vascular plexus [11]. They can be seen in the normal scalp and in many scalp disorders; according to Rudnicka et al. [12], radial, thin, arborizing vessels, associated with large yellow dots, are characteristic for LED. This feature is sometimes referred to as 'red spider in yellow dots'.

Red Dots. These are described by Miteva and Tosti [11] and by Tosti et al. [13] as erythematous, polycyclic, concentric structures, regularly distributed around the follicular ostia and associated with widened ostia, telengectasia and extravased erythrocytes. They are a helpful trichoscopic clue in evidencing active LED. They are believed to be a positive prognostic factor [12] and can also be observed in PSO.

\section{Pigment Pattern}

A diffuse, honeycomb pigment pattern is classically seen in normal scalp and is more pronounced in individuals with darker skin shades. Bald areas and areas with sparse hair, as seen in men with advanced AGA, have a darker pigment network which corresponds to tanning due to excessive sun exposure. In general, the extent correlates with the degree of hair loss; it was diffuse in bald scalp and patchy when some hair remained in the area. This pattern is characterized by grids (irregular lines) and holes. The lines are hyperchromic and represent melanotic rete ridges, whereas the holes represent the hypochromic suprapapillary epidermis [7].

The observation of a patchy honeycomb pigment pattern in bald areas affected by LED and the actinically damaged scalp is not unexpected. The honeycomb pigment pattern appears to be a marker of chronic disease, given its appearance large- ly in conditions of alopecia that can be persistent or slowly progressive.

\section{Follicular Pattern}

Trichoscopy can describe features of follicle opening called 'dots' that can be normal, empty, fibrotic or containing keratotic or sebaceous material. These are the most common follicular features, summarized in table 2.

Yellow Dots. These appear as round or polycyclic yellow to yellow-pink dots and are known to represent the follicular infundibulum, distended with degenerating keratinocytes and sebum. They are the most common and most sensitive feature of AA, but are also seen in some case of AGA and AA incognita. Yellow dots in AA are keratinous, whereas they represent sebaceous debris in AGA [7]. Karadağ Köse and Güleç [8] reported a higher prevalence in AA $(83.7 \%)$ than in AGA (30.5\%). The predominance of yellow dots in the frontal area compared to the occipital area favors the diagnosis of female androgenic alopecia. The authors suggest they are highly sensitive, but not a specific marker for AA. In $\mathrm{AA}$, they correlate with disease severity [11].

White Dots. These appear as big, irregular, pale white dots and are seen in scarring alopecias such as lichen planopilaris (LPP), LED and FD. They represent destroyed follicles that are replaced by fibrous tracts (perifollicular fibrosis) with focal loss of melanin [14] and are better seen in darkskinned individuals or over the tanned areas in light-skinned individuals. They have to be distinguished by the small, regular, pinpoint white dots that are observed in sun-exposed areas and in dark-skin phototypes regardless of hair loss. They correspond to eccrine duct openings $[12,15]$.

Black Dots. These represent stubs of hairs (cadaverized hairs) that are fractured before their emergence from the scalp in patients affected by AA, where they are a sign of disease activity [11]. Broken hairs are not exclusive to AA, as they are seen in trichotillomania, dissected cellulitis, tinea capitis, chemotherapy-induced alopecia and in trichoteiromania (friction alopecia caused by constant rubbing of the scalp).

Blue-Gray Dots. These are an expression of melanophages in papillary dermis and indicate incontinentia pigmenti. They are a feature of two scalp diseases, namely LED and LPP, where they assume two different aspects: in LPP, blue-gray dots appear with a 'target pattern' due to the circu- 
Table 1. Clinicopathological correlation of interfollicular dermoscopic patterns

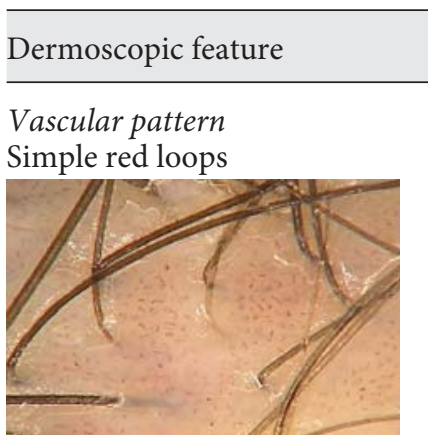

Clinical appearance

Multiple, relatively evenly spaced, fine, red, lasso-shaped loops
Pathology

Dermal papilla capillaries associated with the presence of a scalp epidermis of normal thickness
Associated diseases

PSO

$\mathrm{SD}$

$\mathrm{AD}$

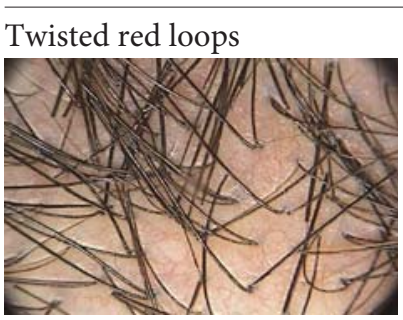

Arborizing red lines

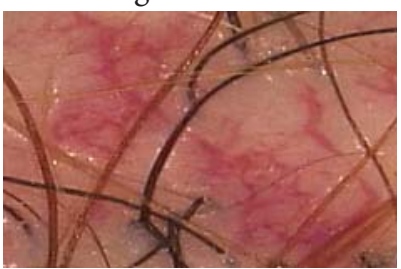

Red dots

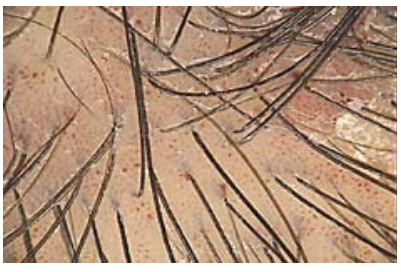

Multiple, relatively evenly spaced, spiral-shaped, twisted loops
Dilated capillaries in dermal papillae observed in the conditions of epidermal hypertrophy (acanthosis)
PSO

FD
Pigment pattern

Honeycomb pigment pattern

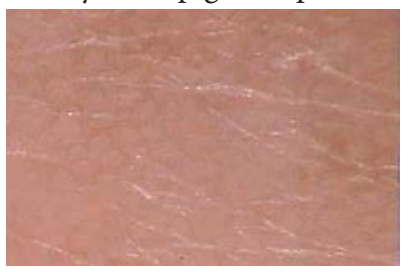

Erythematous, polycyclic, concentric structures, regularly distributed in and around follicular ostia
Subpapillary vascular plexus

LED with a wider caliber than loops of branching vessels

$\mathrm{AD}=$ Atopic dermatitis.

lar arrangement of melanin around the perifollicular area, sparing the interfollicular area [16], unlike LED, where blue-gray dots follow a speckled pattern indicating an involvement of the interfollicular areas

Scalp and Hair Trichoscopic Features with a sprinkling of melanin in these areas $[7,17]$.

Empty Follicles. These appear as skincolored small depressions without hairs. They are observed in AGA, telogen efflu- vium and AA. In AGA, they can appear as raised with dots due to presence of hypertrophied sebaceous units, a consequence of androgen sensitivity [7]. Yet, kenogen hair follicles in healthy scalps can display a sim-
AGA

Balding areas 
Table 2. Clinicopathological correlation of follicular dermoscopic patterns

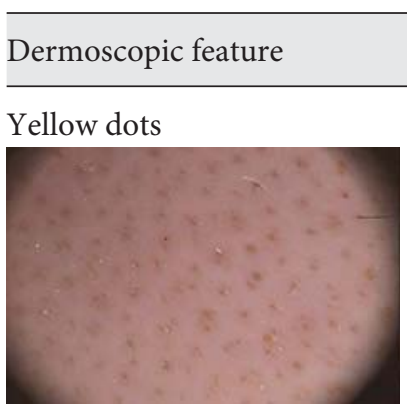

Pathology

Dilated infundibula plugged

with sebum and keratin
Associated diseases

Round or polycyclic yellow to

yellow-pink dots
AA

AAI

AGA

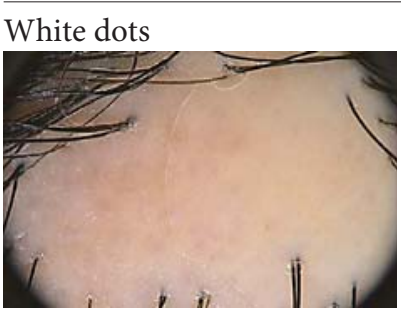

Big, irregular, pale white dots

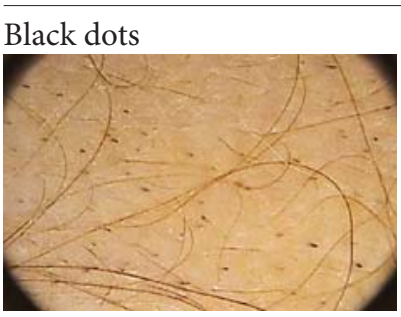

Black dots inside follicular opening

\section{Destroyed follicles replaced LED \\ by fibrous tracts \\ FD \\ LPP}

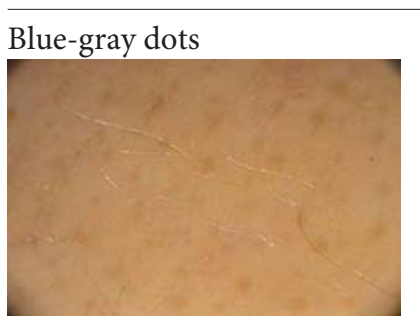

Speckled pattern

Target pattern
Stubs of hair fractured before their emergence from the scalp
AA
Tricotillomania
DC
Tinea capitis
Chemotherapy
Trichoteiromania

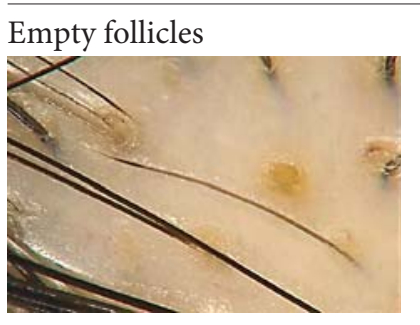

Melanophages in papillary LED

dermis
Skin-colored small

depressions without hairs

Empty infundibula

AGA

TE

AA 
Table 2 (continued)

\begin{tabular}{llll}
\hline Dermoscopic feature & Clinical appearance & Pathology & Associated diseases \\
\hline Tapering hairs & $\begin{array}{l}\text { Exclamation mark hairs } \\
\text { Coudability hairs }\end{array}$ & $\begin{array}{l}\text { Fractured hair with a } \\
\text { frayed thicker tip } \\
\text { Hairs with a narrowed } \\
\text { proximal shaft }\end{array}$ & AA \\
& & & \\
& &
\end{tabular}

\begin{tabular}{|c|c|c|c|}
\hline Broken hairs & $\begin{array}{l}\text { Fractured hairs at different } \\
\text { distances from the scalp }\end{array}$ & Broken shafts & $\begin{array}{l}\text { AA } \\
\text { Tricotillomania }\end{array}$ \\
\hline
\end{tabular}

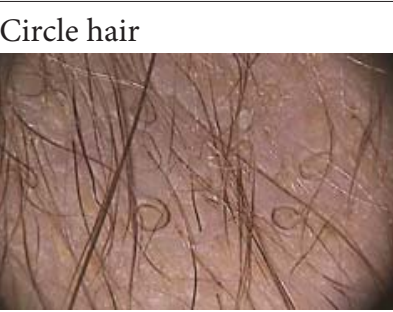

$\begin{array}{ll}\text { Thin, short, intracorneum } & \text { Vellus-like follicles } \\ \text { hairs that form a circle } & \text { AA } \\ & \text { TE }\end{array}$

Follicular keratotic plugging

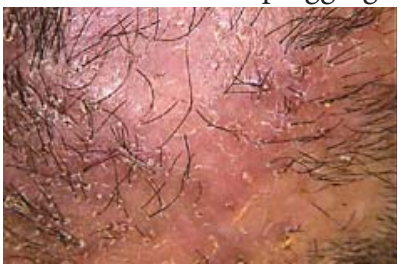

Tufted hair

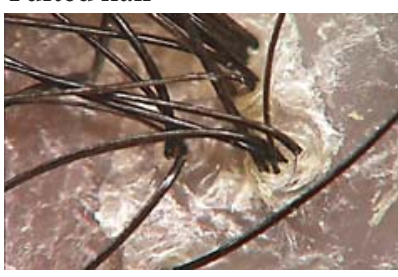

Keratotic masses plugging follicular ostia
Hyperkeratosis and plugging of follicular ostia by keratotic material
LED

TA

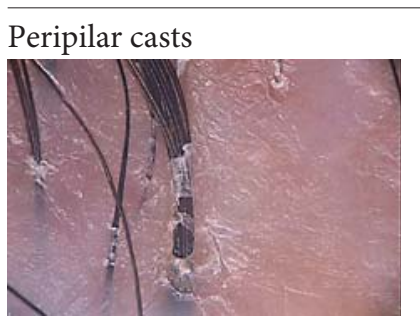

Tufts of $>6$ hairs emerging from the same ostium
Compound follicular structures
FD

Acne keloidalis
Concentrically arranged scales encircling emerging hair shaft
Perifollicular inflammation

LPP

AFF

LED

PSO

SD

Keratinization disorders 
Table 2 (continued)

\begin{tabular}{llll}
\hline Dermoscopic feature & Clinical appearance & Pathology & Associated diseases \\
\hline Peripilar sign (brown halo) & $\begin{array}{l}\text { Brown halo surrounding } \\
\text { follicular opening }\end{array}$ & Perifollicular inflammation & AGA \\
\hline Hair diameter diversity (anisotrichia) & Hair diameter variability & Hair shaft variability & AGA \\
TE & & \\
\end{tabular}

$\mathrm{AAI}=$ Alopecia areata incognita $\mathrm{DC}=$ dyskeratosis congenita; $\mathrm{TE}=$ telogen effluvium.

ilar appearance, so they can be noticed both in AGA and in controls [8].

Absence of Follicular Opening. This is a sign of fibrosis and occurs in all forms of scarring alopecia, such as LED and LPP; thus, they can be considered a hallmark of these scalp diseases.

Tapering Hairs. These include exclamation mark hairs and coudability hairs and are a marker for the activity and severity of AA $[18,19]$. Exclamation mark hairs are fractured hairs due to intense lymphocytic infiltration [20] and present a frayed thicker tip, while coudability hairs are described as hairs with a narrowed proximal shaft. According to Inui [21], they are mostly found in the scalp surrounding the patch.

Broken Hairs. These are fractured at different distances from the scalp. According to Karadağ Köse and Güleç [8], they are suggestive but not specific of AA because they can also be found in patients with trichotillomania.

Circle Hairs. These are described as thin, short intracorneal hairs that form a circle [22] and represent vellus-like follicles that can be seen in AGA, AA and telogen effluvium. In AGA, they are one of the criteria for its diagnosis; Rakowska et al. [23] have, in fact, proposed major and minor criteria for the diagnosis of AGA. Major criteria include: $(1)>4$ yellow dots in the frontal area; (2) lower than average hair thickness in the frontal area compared with the occiput, and (3) $>10 \%$ thin hairs in the frontal area. Minor criteria include: (1) increased frontal to occipital ratio of single hair pilosebaceous units; (2) vellus hair, and (3) perifollicular discoloration (peripilar sign or brown halo). The presence of 2 major criteria or 1 major plus 2 minor criteria leads to the diagnosis of AGA with 98\% specificity. The same authors believe that the presence of $>10 \%$ thin hairs in the frontal area is by itself highly suggestive for the diagnosis. Circle hairs can also be detected in AA, where they can be a predominant feature in some patients and represent a particular expression of short vellus hair (diameter $<10 \mathrm{~mm}$ ); the latter may be white and is most prevalent in the remitting stage of AA [24].

Follicular Keratotic Plugging. This relates to keratin material occluding the dilated infundibular openings and is a specific feature of LED, where it is an expression of hyperkeratosis and the plugging of follicular ostia by keratotic material.

Tufted Hairs. These are the hallmark of FD, where they appear as multiple $(>6)$ hairs emerging from a single dilated follicular opening. They are an expression of a compound of follicular structures and are seen in advanced cases, both clinically and by trichoscopy. Tufted hairs can be seen also in acne keloidalis, LPP and central cen- trifugal alopecia; however, in these conditions the tufts consist only of 2-3 hairs [25, 26].

Peripilar Casts. These are an expression of perifollicular inflammation and appear as concentrically arranged scales encircling the emerging hair shaft. They are seen and described above all in LPP, but can be appreciated, more generally, in scarring (frontal fibrosing alopecia, LED) and nonscarring alopecia (PSO, SD and keratinization disorders). Peripilar casts are better appreciated with the use of polarized dry dermatoscopy $[7,11]$.

Peripilar Sign (Brown Halo). This is a specific feature of AGA, seen in the early stage, that appears as a brown halo, roughly $1 \mathrm{~mm}$ in diameter, around the follicular ostium. Pathological studies correlated the peripilar sign to perifollicular inflammation in Caucasians $[27,28]$. Inui [21] speculated that in Asians the peripilar sign is a result of postinflammatory perifollicular pigmentation.

Hair Diameter Diversity (Anisotrichia). Trichoscopy of AGA is characterized by a hair diameter variability of $>20 \%$, which is a very important distinguishing feature [29]. Hair shaft variability can be also seen in AA and telogen effluvium, although in AA, dermatoscopy shows uniform miniaturization [30]. Hair diameter variety is very useful to detect early AGA, also in children. 


\section{Discussion}

The inflammatory scalp diseases are divided into 2 groups: associated or not associated with alopecia. The first group comprises, in turn, scarring and nonscarring alopecia. The term 'scarring alopecia' encompasses a group of scalp disorders characterized by the permanent destruction of hair follicle. In primary scarring alopecias, the pilosebaceous follicle is the target of the destructive process. Most of the primary scarring alopecias have neither a known cause nor a consistent clinical/ pathologic picture. Clinical and histopathologic features present along a broad spectrum, change over time and often overlap, making accurate diagnosis challenging for both clinicians and dermatopathologists. This group includes the following clinical entities: LPP, LED, frontal fibrosing alopecia, pseudopelade of Brocq, central centrifugal alopecia, FD and tufted folliculitis [31]. LPP and LED are the most frequent causes of lymphocytic primary scarring alopecia. They are characterized by microscopic evidence of interface dermatitis involving the dermoepidermal junction and/ or the adnexal epithelium. The differential diagnosis usually requires a histopathological examination. A biopsy should be taken from a scalp area that shows signs of inflammation [32]. However, trichoscopy can be useful to differentiate the 2 entities [17], although some aspects, such as white dots, can be observed in both of them. Frontal fibrosing alopecia is considered a clinical variant of LPP, with a smaller follicular lymphocytic infiltration and a wide range of apoptotic cells $[33,34]$.

$\mathrm{AA}$ is among the most common forms of nonscarring alopecia [35]. The broadest study on trichoscopy of AA was performed by Lacarrubba et al. [2], Ross et al. [5] and Inui [21]. The results indicate that black

\section{References}

1 Rudnicka L, Olszewska M, Majsterek M, Czuwara J, Slowinska M: Presence and future of dermoscopy. Expert Rev Dermatol 2006;1: 769-772.

2 Lacarrubba F, Dall'Oglio F, Rita Nasca M, Micali G: Videodermatoscopy enhances diagnostic capability in some forms of hair loss. Am J Clin Dermatol 2004;5:205-208.

3 Olszewska M, Rudnicka L: A novel method for diagnosing and monitoring androgenic alopecia. Dermatology 2006;212:290-291. dots and exclamation mark hairs are markers of high disease activity, while yellow dots predominate in long-lasting alopecia and are the most sensitive markers of disease [11].

SD and PSO are the most frequent causes of inflammatory scalp disease not associated with alopecia $[36,37]$ : the vascular pattern is the most important trichoscopy aspect to differentiate the 2 entities; in fact, in scalp PSO, twisted red loops, red dots and lice-like blood vessels [6] are observed, where in SD arborizing and atypical vessels are observed. AGA is a transitional alopecia, because of its scarring evolution [38]. It is characterized by anisotrichia, miniaturized hair, yellow dots, circle hair, brown halo and empty follicles.

Trichoscopy is a very useful instrument for the clinician to achieve a correct diagnosis of most scalp diseases. It allows to differentiate nonscarring from scarring alopecia without making scalp biopsies. Moreover, trichoscopy is a noninvasive technique that does not require expensive instruments and is very well accepted by patients. Another advantage of the method is that it is useful not only for the diagnosis, but also to evaluate the activity phase of disease and the therapeutical response to the treatment [39]. In AA, for example, it is able to recognize and distinguish yellow spots, which are a sign of disease severity, from exclamation mark hairs, which are a sign of disease activity. Despite these qualities, trichoscopy has the limitation of not recognizing a pathognomonic aspect for each scalp disease, which in every case requires a deep and good anamnesis, associated with a careful physical examination in which trichoscopy plays a predominant role. In rare cases, a biopsy is necessary. On the other hand, information revealed by trichoscopy may require a biopsy, which in itself is not often diagnostically determinative.
All dermatoscopes can also be used for trichoscopy. However, the optimal evaluation of scalp vascular patterns requires a magnification greater than $\times 20$. Images can be acquired by attaching a dermatoscope (Dermlite ${ }^{\circledR}, 3$ Gen LLC, San Juan Capistrano, Calif., USA) to a digital camera, which also allows for the zooming of the images $[8,40]$. Special dermatoscopes that attach to an iPhone ${ }^{\circledR}$ (Apple, Cupertino, Calif., USA) have been developed by FotoFinder ${ }^{\circledR}$ Systems (Handyscope ${ }^{\circledR}$, Bad Birnbach, Germany) and Canfield ${ }^{\circledR}$ (DermScope $^{\circledR}$, Fairfield, N.J., USA). For the trichoscopic analysis, we can also use digital computerized dermatoscopy that requires an optical instrument through lenses with a magnification power from $\times 20$ to $\times 1,000$. However, most trichoscopy data have been obtained with the FotoFinder Dermoscope ${ }^{\circledR}$. Trichoscopy can be performed either with or without alcohol/ water as an interface solution [5, 41]. Dry dermatoscopy is useful to examine scalp conditions with diffuse or perifollicular scaling. The use of a digital camera allows to evaluate the deeper skin structures not visible to the naked eye. The method allows to take a photograph and then store the scanned images to compare them in future follow-ups [7, 42].

In short, trichoscopy offers a means for viewing aspects of normal and diseased scalp and hair, holding great promise as a tool for enhanced clinical care and for a greater understanding of disease. Moreover, trichoscopy is also useful to evaluate the treatment response in all these disorders.

\section{Disclosure Statement}

The authors declare to have no conflicts of interest.
4 Olszewska M, Rudnicka L: Effective treatment of female androgenic alopecia with dutasteride. J Drugs Dermatol 2005;4:637640.

5 Ross EK, Vincenzi C, Tosti A: Videodermoscopy in the evaluation of hair and scalp disorders. J Am Acad Dermatol 2006;55:799-806.

6 Rossi A, Mandel VD, Garelli V, Mari E, Fortuna MC, Carlesimo M, Richetta A, Scarnò M, Trucchia A, Calvieri S: Videodermoscopy scalp psoriasis severity index (VSCAPSI): a useful tool for evaluation of scalp psoriasis. Eur J Dermatol 2011;21:546-551.

7 Jain N, Doshi B, Khopkar U: Trichoscopy in alopecias: diagnosis simplified. Int J Trichology 2013;5:170-178.

8 Karadağ Köse Ö, Güleç AT: Clinical evaluation of alopecias using a handheld dermatoscope. J Am Acad Dermatol 2012;67:206-214.

9 RyanTJ: Microcirculation in psoriasis: blood vessels, lymphatics and tissue fluid. Pharmacol Ther 1980;10:27-64. 
10 Kim GW, Jung HJ, Ko HC, Kim MB, Lee WJ, Lee SJ, Kim DW, Kim BS: Dermoscopy can be useful in differentiating scalp psoriasis from seborrhoeic dermatitis. Br J Dermatol 2011; 164:652-656.

11 Miteva M, Tosti A: Hair and scalp dermatoscopy. J Am Acad Dermatol 2012;67:10401048.

12 Rudnicka L, Olszewska M, Rakowska A, Slowinska M: Trichoscopy update 2011. J Dermatol Case Rep 2011;5:82-98.

13 Tosti A, Torres F, Misciali C, Vincenzi C, Starace M, Miteva M, Romanelli P: Follicular red dots: a novel dermoscopic pattern observed in scalp discoid lupus erythematosus. Arch Dermatol 2009;145:1406-1409.

14 Kossard S, Zagarella S: Spotted cicatricial alopecia in dark skin. A dermoscopic clue to fibrous tracts. Australas J Dermatol 1993;34 49-51.

15 Abraham LS, Piñeiro-Maceira J, Duque-Estrada B, Barcaui CB, Sodré CT: Pinpoint white dots in the scalp: dermoscopic and histopathologic correlation. J Am Acad Dermatol 2010; 63:721-722.

16 Duque-Estrada B1, Tamler C, Sodré CT, Barcaui CB, Pereira FB: Dermoscopy patterns of cicatricial alopecia resulting from discoid lupus erythematosus and lichen planopilaris. An Bras Dermatol 2010;85:179-183.

17 Ankad BS, Beergouder SL, Moodalgiri VM Lichen planopilaris versus discoid lupus erythematosus: a trichoscopic perspective. Int J Trichology 2013;5:204-207.

18 Rossi A, Cantisani C, Carlesimo M, Scarnò M, Scali E, Mari E, Garelli V, Maxia C, Calvieri S: Serum concentrations of IL-2, IL-6, IL-12 and TNF- $\alpha$ in patients with alopecia areata. Int J Immunopathol Pharmacol 2012;25:781-788.

19 Dy LC, Whiting DA: Histopathology of alopecia areata, acute and chronic: why is it important to the clinician? Dermatol Ther 2011; 24:369-374
20 Whiting DA: Structural abnormalities of the hair shaft. J Am Acad Dermatol 1987;16:1-25.

21 Inui S: Trichoscopy for common hair loss diseases: algorithmic method for diagnosis. J Dermatol 2011;38:71-75.

22 Miteva M, Tosti A: Dermatoscopy of hair shaft disorders. J Am Acad Dermatol 2013;68: 473-481.

23 Rakowska A, Slowinska M, Kowalska-Oledzka E, Olszewska M, Rudnicka L: Dermoscopy in female androgenic alopecia: method standardization and diagnostic criteria. Int J Trichology 2009;1:123-130.

24 D'Ovidio R: Alopecia areata: news on diagnosis, pathogenesis and treatment. G Ital Dermatol Venereol 2014;149:25-45.

25 Otberg N, Kang H, Alzolibani AA, Shapiro J: Folliculitis decalvans. Dermatol Ther 2008; 21:238-244

26 Fabris MR, Melo CP, Melo DF: Folliculitis decalvans: the use of dermatoscopy as an auxiliary tool in clinical diagnosis. An Bras Dermatol 2013;88:814-816.

27 Whiting D: Dermatopathology of common hair problems. J Cutan Med Surg 1999(suppl 3):S3-S13.

28 Deloche $\mathrm{C}$, de Lacharrière $\mathrm{O}$, Misciali $\mathrm{C}$, Piraccini $\mathrm{BM}$, Vincenzi C, Bastien $\mathrm{P}$, Tardy I, Bernard BA, Tosti A: Histological features of peripilar signs associated with androgenetic alopecia. Arch Dermatol Res 2004;295:422428.

29 De Lacharrière O, Deloche $\mathrm{C}$, Misciali C, $\mathrm{Pi}$ raccini BM, Vincenzi C, Bastien P, Tardy I, Bernard BA, Tosti A: Hair diversity: a clinical sign reflecting the follicle miniaturization. Arch Dermatol 2001;137:641-646.

30 Piraccini BM, Alessandrini A: Androgenetic alopecia. G Ital Dermatol Venereol 2014;149: $15-24$.

31 Mirmirani P1, Willey A, Headington JT, Stenn K, McCalmont TH, Price VH: Primary cicatricial alopecia: histopathologic findings do not distinguish clinical variants. J Am Acad Dermatol 2005;52:637-643.
32 Agozzino M, Tosti A, Barbieri L, Moscarella E, Cota C, Berardesca E, Ardigò M: Confocal microscopic features of scarring alopecia: preliminary report. Br J Dermatol 2011;165: 534-540.

33 Rossi A, Iorio A, Scali E, Gerardi M, Priolo A, Misciali C, Carlesimo M, Calvieri S, Mari E: Frontal fibrosing alopecia and lichen planopilaris: clinical, dermoscopic and histological comparison. Eur J Inflamm 2013;11:311-314.

34 Toledo-Pastrana T, Hernández MJ, Camacho Martínez FM: Perifollicular erythema as a trichoscopy sign of progression in frontal fibrosing alopecia. Int J Trichology 2013;5 151-153.

35 Seetharam KA: Alopecia areata: an update. Indian J Dermatol Venereol Leprol 2013;79: 563-575.

36 Ooi ET, Tidman MJ: Improving the management of seborrhoeic dermatitis. Practitioner 2014;258:23-36.

37 Gupta AK, Bluhm R: Seborrheic dermatitis. J Eur Acad Dermatol Venereol 2004;18:13-26.

38 Won CH, Kwon OS, Kim YK, Kang YJ, Kim BJ, Choi CW, Eun HC, Cho KH: Dermal fibrosis in male pattern hair loss: a suggestive implication of mast cells. Arch Dermatol Res 2008;300:147-152.

39 Rossi A, Iorio A, Scali E, Fortuna MC, Mari E, Palese E, Greco P, Carlesimo M: Monilethrix treated with minoxidil. Int J Immunopathol Pharmacol 2011;24:239-242.

40 Silverberg NB, Silverberg JI, Wong ML: Trichoscopy using a handheld dermoscope: an in-office technique to diagnose genetic disease of the hair. Arch Dermatol 2009;145: 600-601.

41 Micali G, Lacarrubba F, Massimino D, Schwartz DA: Dermatoscopy: alternative uses in daily clinical practice. J Am Acad Dermatol 2011;64:1135-1146.

42 Pierard-Franchimont C, Uhoda E, Pierard GE: Quantification of dandruff adherence to hair. Int J Cosmet Sci 2005;27:279-282. 